\title{
LA ACADEMIA NACIONAL DE MEDICINA Y EL INSTITUTO NACIONAL DE SALUD: INSTITUCIONES TUTELARES DE LA SALUD PÚBLICA Y DE LA INVESTIGACIÓN MÉDICO CIENTÍFICA DEL PERÚ
}

\author{
THE NATIONAL ACADEMY OF MEDICINE AND THE NATIONAL INSTITUTE OF HEALTH:TUTELARY \\ INSTITUTIONS OF THE PUBLIC HEALTH AND SCIENTIFIC MEDICAL RESEARCH IN PERU
}

Zuño Burstein ${ }^{1, a}$

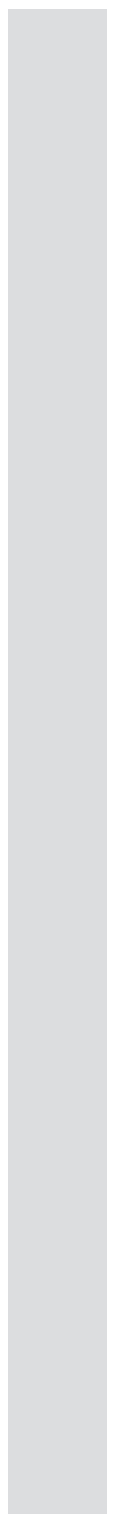

La Academia Nacional de Medicina es la institución médico - científica de mayor nivel jerárquico en el Perú que formalizó su creación por Ley el año 1888. Tiene responsabilidad de carácter académico como organismo asesor del Estado y del Gobierno Peruano en problemas de salud pública de interés nacional, y goza por Ley de autonomía organizativa y administrativa. Sus miembros son profesionales de alta competencia en el ámbito profesional, académico, cultural y ético; admiten, por invitación y calificación rigurosa, a 40 académicos de número y 80 asociados, cuentan, además, con un limitado número de distinguidos miembros designados como académicos honorarios y académico correspondientes.

La presidencia de la Academia Nacional de Medicina es elegida por la asamblea de académicos de número; esta presidencia, a través de su historia, ha sido ocupada por destacados médicos de prestigio internacional. En el reciente bienio 2011-2012 la presidencia ha sido desempeñada con reconocida y elogiada competencia por el Dr. Alberto Perales Cabrera, médico psiquiatra, profesor principal de la Facultad de Medicina Humana "San Fernando" de la Universidad Nacional Mayor de San Marcos y exdirector del Instituto de Ética de dicha casa de estudios.

El Dr. Alberto Perales en su discurso como presidente saliente de la Academia Nacional de Medicina dijo textualmente que: La Academia Nacional de Medicina, no es una sociedad científica más, sino una morada profesional del pensamiento con una visión integral de las ciencias, las artes, la sociedad y la cultura, y cuya especial responsabilidad es orientar en el campo de su competencia a los poderes públicos del Estado. Su tarea es contribuir al estudio científico de los grandes problemas nacionales de salud y ofrecer la opinión técnica pertinente para colaborar a la estructuración de la sociedad que todos deseamos, solidaria, comprometida e inclusiva, y al engrandecimiento de nuestra nación.

En su balance de gestión el Dr. Perales, destacó entre los logros obtenidos el /...Reposicionamiento de la Academia en el cumplimiento del mandato de su ley fundacional de ser ente consultivo de los poderes públicos. Recordó que durante el año 2012 el presidente de la República del Perú, Ollanta Humala, había recurrido oficialmente a la Academia para que brinde asesoría y estudie varios problemas concretos de interés en la salud pública del país, encargo que la Academia cumplió rápidamente designando grupos de estudios específicos para cada tema, cuyas conclusiones y recomendaciones fueron entregados oportunamente al señor presidente de la República quien las acogió y les dio el curso pertinente a través del Ministerio de Salud.

Esta importante y positiva relación con el Poder Ejecutivo se vio reflejada con la concurrencia del presidente Ollanta Humala y su ministro de salud Dr. Alberto Tejada a la solemne ceremonia que la Academia Nacional de Medicina celebra anualmente conmemorando las Fiestas Patrias Nacionales en julio de 2012, donde ambas autoridades gubernamentales expresaron su beneplácito con el desempeño y colaboración de la Academia y comprometieron una cercana interrelación.

\footnotetext{
Instituto Nacional de Salud. Lima, Perú.

Director de la RPMESP

Recibido: 15-03-13 Aprobado: 20-03-13
}

Citar como: Burstein Z. La Academia Nacional de Medicina y el Instituto Nacional de Salud: instituciones tutelares de la salud pública y de la investigación médico científica del Perú [Editorial]. Rev Peru Med Exp Salud Publica. 2013;30(1):9-11. 
El Dr. Perales, en el discurso citado destacó, entre otros importantes logros de la institución, el establecimiento de sendos convenios de cooperación y mutua colaboración, ya en provechosa ejecución, con el Instituto Nacional de Salud del MINSA y también con la Peruvian American Medical Society (PAMS), y en proceso final con la Comisión Nacional para el Desarrollo y Vida sin Drogas (DEVIDA).

Para el 2013, el Dr. Roger Guerra García asume el cargo de presidente de la Academia Nacional de Medicina. El Dr. Guerra es un destacado médico investigador que tiene una importante y amplia trayectoria institucional con cargos de gran responsabilidad, como haber sido presidente del Consejo Nacional de Ciencia y Tecnología (CONCYTEC), congresista de la República, presidente de la Academia Nacional de Ciencias, entre otras; y que ha asumido el cargo con el compromiso expresado, de continuar y dinamizar los compromisos y responsabilidades que la Academia tiene por ley y los adquiridos en la gestión del Dr. Perales, garantizando así la continuidad del rol que esta importante institución cumple en beneficio del país.

El Instituto Nacional de Salud es actualmente un Organismo Público Ejecutor del Ministerio de Salud del Perú, con personería jurídica de derecho público interno y autonomía económico-administrativa, desempeña el rol de brazo científico de esta entidad del Estado. Está integrado por los denominados: Centro Nacional de Salud Pública; Centro Nacional de Salud Intercultural; Centro Nacional de Productos Biológicos; Centro Nacional de Control de Calidad; Centro Nacional de Salud Ocupacional y Protección del Ambiente para la Salud, y el Centro Nacional de Alimentación y Nutrición, los que pretéritamente eran importantes institutos individualizados de investigación; de producción de biológicos; de prestación de servicios altamente especializados y capacitación de personal técnico; y en los que se ha realizado valiosas investigaciones en dolencias nacionales nativas endémicas como la enfermedad de Carrión, la leishmaniosis tegumentaria, las micosis profundas, y enfermedades infectoparasitarias tropicales; así como en otras que causaron gran impacto sanitario como la lepra, la viruela, la tuberculosis, hepatitis viral B, malaria, el cólera, entre otras.

El actual jefe institucional del Instituto Nacional de Salud, Dr. César Cabezas Sánchez, médico salubrista especialista en enfermedades infeccionas y tropicales, profesor principal de la Facultad de Medicina de la Universidad Nacional Mayor de San Marcos y académico asociado de la Academia Nacional de Medicina, ha planteado como estrategia de gestión el denominado Plan Estratégico Institucional 2011-2013 en el que el Instituto
Nacional de Salud deja de ser un gran laboratorio -como fue visto tradicionalmente- para ir convirtiéndose en el ente rector de la investigación en salud para que esta contribuya efectivamente a mejorar la salud de nuestra población. En este plan estratégico, define la nueva cultura organizacional enmarcada en los compromisos que el país ha asumido tanto a nivel nacional como internacional fundamentalmente, en documentos técnicos y normativos que orientan la respuesta nacional sectorial e institucional a los problemas de salud del país.

El Instituto Nacional de Salud bajo la actual gestión ha continuado a través de sus diferentes estructuras técnico-administrativas con la producción de biológicos e insumos de su competencia entre los que la producción de ciertas vacunas de interés nacional está siendo tramitada así como otros productos estratégicos que contribuyen a los programas sociales implementados; el INS realiza el control de calidad de medicamentos en un laboratorio acreditado internacionalmente y que es referente de la OMS. Participa en la reducción de la desnutrición infantil crónica, estudia y genera evidencias para afrontar las enfermedades ocupacionales y las inducidas por los cambios ambientales; se ocupa de dar un enfoque de interculturalidad en las intervenciones que se realizan, lo cual es de vital importancia en el país. Tiene, además, la responsabilidad de controlar la red de laboratorios especializados a nivel nacional y la capacitación del personal técnico de laboratorio.

Al Instituto Nacional de Salud se le asignó la responsabilidad de ser el coordinador de los Institutos Nacionales de Salud de la Unión de Naciones Sudamericanas que la integran doce países de la región, y es el referente para América en el control de calidad con acreditación internacional para el control de ciertos medicamentos que se usan contra de la malaria, tuberculosis y otras enfermedades. Por último, además de varias medidas de reordenamiento interno, se ha consolidado con facultades de medicina peruanas, con el Municipio de Lima en especial con la Academia Nacional de Medicina, importantes convenios de colaboración interinstitucional.

Parte de la función fundamental del Instituto es la investigación biomédica, para ello es necesario obtener la información necesaria en la priorización de objetivos y la toma de decisiones sobre las políticas sanitarias, que deben ir más allá de las buenas intenciones. La transformación para un sistema de salud con equidad y eficiencia pasa por la implementación de decisiones con una sólida base científica basadas en las mejores evidencias posibles. En este sentido, el contar con un medio de difusión de las investigaciones médico científicas relevantes en nuestro país que permita enfrentar los retos en salud, es una obligación para el Estado. 
La Revista Peruana de Medicina Experimental y Salud Pública que ha cumplido el año pasado año su 70 aniversario de creación como organismo oficial de difusión científica del Instituto Nacional de Salud cumple este objetivo.

Con estos principios establecidos y compatibilizándolos con los convenios concertados entre la Academia Nacional de Medicina, como organismo oficial asesor del gobierno en problemas de salud pública y el Instituto Nacional de Salud, organismo ejecutor de las políticas de salud en las áreas de su competencia ya señaladas, se organizó un ciclo de conferencias conjuntas de estas dos instituciones, en fechas coincidentes con la publicación de cada uno de los números de la Revista Peruana de Medicina Experimental y Salud Pública, en las que se presentaba y discutía el tema principal que había sido publicado en ese número; se invitó para tal efecto a autoridades y expertos en el tema aludido, con el objetivo de sacar conclusiones y elevar las recomendaciones pertinentes al gobierno, o a quien correspondiera.

Se debe destacar, al hacer un balance de lo logrado en ese pasado año, que se ha cumplido satisfactoriamente con las "metas y proyecciones al futuro" programadas y publicadas en el Editorial del primer número del año 2012 en las que establecimos el compromiso de contribuir, a través de nuestra publicación, con la política de salud señalada por el gobierno entrante, expresando en sendas comunicaciones dirigidas al presidente constitucional de la República.

Los temas programados y publicados en nuestra Revista durante el año 2012, representan importantes problemas de Salud Pública cuya exposición y deliberación con sus respectivas conclusiones representan contribuciones importantes al país. Estos fueron: "Violencia y Adicciones", "Salud Ocupacional", "Nutrición" y "Ensayos Clínicos".
Para el año 2013 tenemos programados y comprometidos los siguientes temas: para este primer número del año el tema principal es: "Cáncer como problema de salud pública", para el que se ha designado como editor invitado para coordinar este número y presentarlo en la conferencia conjunta de la Academia de Medicina y el Instituto Nacional de Salud que se llevará a cabo en Abril del presente año, al Dr. Mayer Zaharia médico radioóncologo, exjefe del Servicio de Radioterapia del Instituto Nacional de Enfermedades Neoplásicas (INEN), profesor emérito de la Universidad Peruana Cayetano Heredia, académico de número de la Academia Nacional de Medicina y quien ha recibido recientemente el Premio Hipólito Unánue por su destacada labor como investigador científico. El segundo número del año, que será publicado en junio, tendrá como tema principal "La Atención Primaria de la Salud", a cargo, como editor invitado, del Dr. José Somocursio, médico neumólogo cirujano de tórax, ex secretario ejecutivo de EsSalud. El tercer número del año, que se publicará en septiembre, tendrá como tema principal "Salud Sexual y Reproductiva”, a cargo del editor invitado Dr. Oscar Ugarte Ubillús, médico salubrista y ex ministro de salud; mientras que el cuarto número, que se publicará en diciembre de este año, tendrá como tema principal "Inequidad en salud" a cargo del Dr. Jay Kaufmann, profesor e investigador renombrado de la McGill University de Montreal, Canadá.

Consideramos que la Revista Peruana de Medicina Experimental y Salud Pública, revista que tiene un reconocido nivel internacional y que está indexada en varias de las más exigentes bases de datos internacionales por su reconocida calidad, lleva a nivel mundial los problemas de salud del Perú y de nuestra región. Mediante la promoción de las actividades conjuntas entre la Academia Nacional de Medicina y el Instituto Nacional de Salud está contribuyendo con los esfuerzos de mejorar la salud de nuestros países y colaborando con el gobierno peruano en esta importante política de Estado. 